\title{
El Delito Corporativo en el Código Penal Español. Bernardo Feijoo Sánchez (2016). 2a Ed. Pamplona: Civitas
}

\author{
Pedro PÁez Bimos \\ Universidad Rey Juan Carlos
}

\begin{abstract}
El profesor Bernardo Feijoo Sánchez en su obra El Delito Corporativo en el Código Penal Español, nos acerca a un tema de dialéctica, constante en materia de derecho penal económico, esto es el delito corporativo dentro de la legislación espańola. La importancia de esta sub-rama del derecho penal es de transcendencia en las sociedades en vías de industrialización, industrializadas y como diría Silva Sánchez también en las post industrializadas, en donde la realidad económica de los Estados dentro del aspecto de la globalización y la integración supranacional, genera el llamado Derecho penal de la globalización económico (Silva Sánchez, 2011, p. 83), el cual debilita el concepto tradicional de garantismo por su flexibilidad al momento de elaborar la imputación de delitos.
\end{abstract}

En el primer capítulo se aborda el contexto político-criminal en razón de la legalidad y la exigencia que se les da a las personas jurídicas. Y es que mediante la reforma LO 5/2010, del 22 de junio, se introdujo la responsabilidad penal de las personas jurídicas en la legislación española, según dicen muchos autores a base del decreto legislativo 321/2001 (Decreto Legislativo 321/2011, 8 de junio de 2001, "Disciplina della responsabilitá amministrativa delle persona giuridiche, delle societá e delle associazioni anche prive di personalitá giuridica), que promulgó el legislativo italiano, y con su posterior reforma mediante la LO 1/2015 que introdujo los programas de cumplimiento normativo, como una mejora técnica sobre la responsabilidad penal de las personas jurídicas. Estas reformas responden a una realidad criminal que transformó el antiguo aforismo Societas non delinquere potest, puesto que los seres humanos comparten la responsabilidad del sistema jurídico penal con las personas jurídicas, sin perder su protagonismo.

Las personas jurídicas sean estas marginales o multinacionales son sujetos susceptibles de responsabilidad penal por su relevancia dentro del tráfico mercantil, puesto que por su desorganización o por su uso intencional facilitan la comisión de hechos delictivos, siendo esta una característica recogida en los diferentes sistemas del derecho penal moderno. Por lo que según establece Feijoo es de importancia valorar la participación y el rol que las personas jurídicas tienen en la sociedad como su responsabilidad social. Sobre esta responsabilidad existe presión por parte de la comunidad internacional para brindar mecanismos que busquen responder de manera eficaz, siendo uno de estos la autorregulación societaria para evitar delitos, y evitar desproporciones en los procesos penales.

En el capítulo segundo el autor reflexiona sobre la naturaleza de las sanciones a las personas jurídicas, en el cual existen dos puntos de análisis importantes, el primero, busca establecer si en verdad esta se trata de una verdadera y genuina responsabilidad penal, y el segundo, si la persona jurídica es realmente el sujeto de imputación. Si la postura de que el fundamento de la responsabilidad penal es vicarial o por hecho ajeno, son varias las sentencias de la jurisprudencia del Tribunal Supremo - como son las STS 237/2010 y STS 544/2008 sobre la responsabilidad civil subsidiaria de un delito que pueden fundamentar la motivación de esta postura. Robles Planas también fundamenta esta posición estableciendo que existe un sistema de imposición de cargas de la responsabilidad. El autor trabaja sobre la idea propuesta por el sistema anglosajón, la cual determina en el mismo texto que: 'La pena no se basaría tanto en la responsabilidad por un hecho, sino en la ventaja indebida o injustificada que para 
la corporación representa el hecho delictivo" (Feijoo, 2016, p. 41), es decir, la valoración del injusto revisa si existe o no equidad en la relación material entre los costes y el beneficio, por lo tanto quien tenga una ventaja indebida o injustificada deberá responder penalmente en relación a las inversiones realizadas. Sin embargo de adoptar la tesis vicarial o no, lo que sí está claro sobre la responsabilidad de la persona jurídica, es la relación que guarda con la conducta de personas naturales — con sus diferencias en el análisis de imputación—, es así como demuestra el tipo de penas que se le atribuye, lo que algunos autores las denominan cuasi penas.

La exclusión de la responsabilidad empresarial, es el punto central del capítulo tercero, invita al lector a reflexionar sobre la limitación que debe existir en la aplicación del ius puniendi en contra de las empresas, y esto tiene que ver con el carácter autónomo que estas poseen en el juicio de reproche penal, es decir, se debe hacer un ejercicio retrospectivo de sus propios hechos cometidos como eje limitador para equipararse a las teorías que fundamental la responsabilidad civil subsidiaria. Este es el problema que actualmente en la normativa penal ecuatoriana existe con el artículo 49 del COIP y que lo tenía el Código Penal español en su artículo 31 bis antes de la reforma de la LO 1/2015. El autor establece que se deben hacer dos valoraciones importantes de tipo sistémico que se deben realizar sobre las empresas, la primera es la dimensión institucional de la personalidad jurídica, y la segunda la construcción tradicional de la teoría del delito que se basa sobre el concepto de acción culpable por las características del sujeto de imputación, lo que nos lleva a reflexionar sobre el defecto de organización como idea motora para enfrentar el cometimiento de delitos dentro de las organizaciones empresariales.

Como antecedente, es importante recuperar las ideas que el maestro Carlos GómezJara realiza sobre las sociedades policéntricas, es decir aquellas con características de las sociedades modernas que carecen de un sólo centro organizador, y donde si existen diferentes sistemas sociales funcionales que permiten el auto sustento y funcionamiento de diversos centros, en las que se desatacan sus actividades de riesgo y el conocimiento como circunstancias especiales (Gómez-Jara, 2014, p. 11). Es sobre este panorama en el que las sociedades van adquiriendo vida propia y complejidad, cuestión que no es compartida por el autor, sin embargo, más allá de las diferentes perspectivas constructivistas es necesario establecer según Feijoo que dentro del análisis sistémico no se puede dar en base al análisis desde la perspectiva de la sociología organizacional estableciendo que por el dinamismo y su propia cultura corporativa, se esté desligando el factor humano.

La discusión se entorna interesante a posterior, una vez que se interpreta los alcances del artículo 66 bis del Código Penal español, en este caso se valora en conjunto con la circular 1/2016 de la Fiscalía General del Estado y el Auto de 19 de mayo de 2014, en las que se determina que al momento de establecer la responsabilidad de una sociedad mercantil, se debe tomar en cuenta la operación y la capacidad organizativa de la misma, es decir, existen tres grupos importantes de sociedades. La primera tiene que ver con aquellas que operan con normalidad en el mercado, siendo mejor o peor organizadas, las cuales son imputables (para estas se destina el compliance); las segundas tratan sobre las sociedades las cuales comparten de manera mixta su actividad legal con parte ilegal, es decir sociedades que se involucran en delitos como el blanqueo de capitales, terrorismo, entre otros delitos, en este caso siempre que su actividad legal sea mayor a la ilegal, se entenderán imputables; y la tercera se refiere a las sociedades pantallas las cuales son empleadas con el único propósito de cometer delitos, y por lo tanto son inimputables, tal es el caso de sociedades destinadas con el único propósito de defraudar a rentas internas.

Determinadas las sociedades que son o no imputables de responsabilidad penal, el autor aterriza sobre el defecto estructural en relación al cumplimiento de la legalidad, y 
el fundamento de la exención de responsabilidad de los programas de cumplimiento. En el primer caso, se habla de la cultura empresarial, como la unión de varias relaciones personales en un contexto institucional, la cual se conforma por la práctica y la ética, y su defecto es lo que produce el cometimiento de delitos, produciendo en cierta medida una irresponsabilidad estructural, tal como Heine y Gómez-Jara lo establecen. Sin embargo, el autor no coincide y establece que existe una responsabilidad complementaria del hecho individual cometido por la persona natural, en la que no se difumine el acto individual, él considera y está de acuerdo que no es inconstitucional el establecimiento de la exoneración, puesto que evita que se cometan arbitrariedades por parte del poder judicial. En el segundo caso, la idea de que existe en España un sistema vicarial de responsabilidad penal de las personas jurídicas se descarta, puesto que se reconoce una responsabilidad propia de la empresa a pesar del factor humano integrante del mismo, la obligación de supervisión, vigilancia y control, es el fundamento que gira sobre la reprochabilidad de las sociedades, para que de esta manera el riesgo empresarial se encuentren dentro de los parámetros mínimos.

En el capítulo cuarto, el autor profundiza la relación del delito individual con el delito corporativo, que si bien reconoce que son independientes, puesto que si puede haber condena para la persona jurídica sin necesidad de sancionar a una persona física, no obstante el debate dentro de la doctrina es interesante puesto que se contraponen las tesis de un sector - el cual es respaldado por el autor - en el que determinan que existe una responsabilidad por transferencia o a lo mucho autorresponsabilidad imperfecta, con lo que pregonan una responsabilidad por el hecho propio. Sobre este punto es importante manifestar que si bien la persona física es parte integrante del tipo, esto no quiere decir que sea el fundamento de la responsabilidad de las personas jurídicas, y esto guarda sentido cuando se analiza la culpabilidad, por un lado se puede seguir un proceso penal independiente de la persona física, y otro por la persona jurídica, por lo tanto de cierta forma la esfera de la culpabilidad se mantiene intacta para cada uno.

$\mathrm{El}$ autor procede a analizar dos posturas de interés por parte de la institucionalidad de justicia, la primera es la circular 1/2016 de la Fiscalía General del Estado y la segunda, la sentencia del Tribunal Supremo 154/2016 de 29 de febrero. La postura de la Fiscalía General del Estado, sigue siendo la misma a la de su circular del año 2011, en la que estableció que existe una responsabilidad por transferencia o vicarial, a pesar de reconocer que ha existido cambios sustanciales al integrar los modelos de organización y gestión en la reforma legal del año 2015. $\mathrm{Al}$ mismo tiempo la postura sobre la carga de la prueba de la exención según la Fiscalía es clara, esta le corresponde a la persona jurídica al tener la excusa absolutoria como efecto normativo, mas no como exclusión de la responsabilidad. Sobre estos puntos el autor y gran parte de la doctrina rechazan la concepción absoluta de sostener que existe una responsabilidad vicarial, a lo mucho se estimaría como intermedia. En el caso de la STS 154/2016, esta rechaza la postura de la excusa absolutoria y sostiene que se da sobre la misma naturaleza de la infracción, y defiende la responsabilidad propia de la infracción estableciendo que se debe cuidar la "cultura de cumplimiento que la norma penal persigue".

El autor establece una fórmula importante tras reflexionar las posturas antes mencionadas, estableciendo que: Delito corporativo = Conducta antijurídica persona física + Déficit grave de control, vigilancia y supervisión por parte de terceras personas + Defecto estructural, es decir existe una combinación en la responsabilidad de las persona física con la jurídica, por lo que existe una co-responsabilidad de la persona jurídica del hecho cometido por la persona natural, independientemente que la última sea acreedora a circunscritas que afecten su culpabilidad. Por lo tanto el autor plantea tres tesis finales: La acción típica y antijurídica de la persona física que tenga relación con la persona jurídica y que la beneficie guarda relación 
y transmisión de injusto; es relevante el cumplimiento de deberes de supervisión, vigilancia y control para evitar el cometimiento de delitos, sobre todo en la estructura los empleados encargados deben tener la capacidad de decisión y gestión para realizar estas funciones; la responsabilidad de la persona jurídica en el caso que sus programas de cumplimiento obren de manera eficaz, será excluida.

En el último capítulo a manera de cierre se revisan ciertos elementos de la esencia del delito corporativo. El maestro Bernardo Feijoo Sánchez quiere transmitir dos ideas principales sobre la esencia del artículo 31 bis del Código Penal español, las cuales tienen que ver con el mismo desarrollo del tipo. La primera tiene que ver con la creación por parte del consejo de administración de un organismo de supervisión, vigilancia y control en personas jurídicas que no sean de dimensiones pequeńas, y como segundo punto, el establecimiento de una cultura de cumplimiento dentro de la sociedad la cual impida que los subordinados a ella infrinjan estos deberes de manera fácil. Por lo tanto es interesante ver como el autor dota de relevancia al consejo de administración como órgano clave para emplear diferentes medidas no formales sino sustanciales, con el fin de evitar el cometimiento de las infracciones en el seno y por beneficio propio de las sociedades, es decir, no sólo basta con tener reglamentaciones éticas y estatutos disciplinarios que busquen enfrentar el cometimiento de delitos, es necesario que opere un organismo propio de la empresa que este facultado para reglar, supervisar, sancionar y comunicar a la institucionalidad pública del cometimiento de infracciones dentro de su competencia.

Otros temas sustanciales tratan sobre la representación procesal en los delitos empresariales, en este caso existe en el panorama español dos momentos importantes. Antes de la reforma del año 2015 se entendía a los administradores como representantes sea por la comisión u omisión de la infracción, o por no haber controlado de manera correcta a sus subordinados, sin embargo posterior a la reforma se prescinde del concepto de administrador por el de representante es decir, extendiendo a otras personas que puedan tener capacidad de decisión y gestión importante. El autor sobre este punto concuerda que lo importante desde una perspectiva ontológica es que debe ser una persona que detente de forma directa la competencia de tomar decisiones en nombre de la persona jurídica. Sobre el beneficio que debe tener el cometimiento del delito a la empresa, esta característica permite diferenciar los supuestos de criminalidad de la empresa, de la criminalidad en la empresa, es decir, no todo delito cometido por los empleados o subordinados se deben extender o complementar la responsabilidad de la persona jurídica, debe haber un provecho material directo o indirecto. Sobre la relación de la persona natural la circular de la Fiscalía General 1/2016 tiene lógica al establecer que no es necesaria una vinculación formal del agente, basta que se halle integrado en el perímetro de su dominio social.

El autor es muy crítico sobre la eficacia de los programas de cumplimiento como una solución individual para evitar el cometimiento de infracciones, es necesario que sea conexo el cumplimiento de la legalidad como política institucional de la empresa para que el defecto de organización sea un requisito más completo. Debo manifestar que no es tarea fácil comprender los alcances y las conceptualizaciones expresadas en la monografía de Bernardo Feijoo Sánchez, hablar de derecho penal económico y de la responsabilidad de penal de las personas jurídicas es un tema muy controversial dentro de la doctrina penal, pero sobre todo en el ambiente latinoamericano. No es cuestión de posiciones políticas-académicas en la que muchos autores catalogan de "eurocentrismo" al seguir doctrinas que se desarrollan en sociedades postindustrializadas que por razones económicas y sociopolíticas se encuentran en debates de avanzada que como países latinoamericanos en vías de desarrollo nos vamos acercando a este tipo de realidades. 
Uno de los puntos más importantes que nos señala el autor es la dicotomía de la mínima intervención penal y la expansión del derecho penal, si bien es una necesidad políticocriminal el desarrollo de nuevos tipos penales por la constante creación de nuevos delitos en nuestras sociedades modernas - en palabras de Beck Ulrich "sociedades de riesgo"- es deber primario de la doctrina buscar un punto medio que no violente los principios constitucionales fundamentales del proceso penal, esto permite un gran campo de desarrollo como lectores para explorar nuevas ideas y tesis para evitar un atropello punitivo tanto en las etapas de investigación, instrucción y de juicio de las personas jurídicas. Y de igual forma, por motivos de desarrollo legislativo nos permite trasladar ciertas ideas del contexto español que se creó en el artículo 31 bis, al artículo 49 del Código Orgánico Integral Penal, invitándonos a la reflexión, pero sobre todo a la creación de instituciones jurídicas sólidas y debidamente fundamentadas.

\section{Referencias Bibliográficas}

Gómez-Jara, C. (2014). Cuestiones Fundamentales de Derecho Penal Económico. Madrid: Editorial B de F.

Decreto Legislativo 231/2001 (2001). Disciplina della responsabilitá amministrativa delle persona giuridiche, delle societá e delle associazioni anche prive di personalitá giuridica.

Silva Sánchez, J. (2011). La expansión del Derecho penal. Argentina: Editorial B de F. 